\title{
THE ACTION OF PROCAINE AND PROCAINE AMIDE ON THE HEART
}

\author{
BY \\ PAUL SZEKELY and N. A. WYNNE
}

From the Regional Cardiovascular Department, Newcastle General Hospital, and the Department of Physiology and Pharmacology, King's College, University of Durham

Received October 17, 1953

The depressant action of procaine on the heart muscle has been the subject of several clinical and experimental studies (Wiggers and Wegria, 1940; Burstein, 1946; Uhley and Wilburne, 1948; Schaffer et al., 1950). Procaine was found useful in the treatment of cardiac arrhythmias occurring in anæsthetized patients during cardiac surgery. However, its usefulness in the management of clinical arrhythmias in conscious patients has been found to be greatly limited because of its effects on the central nervous system. More recently, procaine amide was introduced (Mark et al., 1951; Newman and Clark, 1951) and both clinical and experimental observations have suggested that this drug is effective in abolishing various types of cardiac arrhythmias and that it is more suitable for clinical purposes than procaine (Berry et al., 1951; Kinsman et al., 1951; Schlachman et al., 1951; Stearns et al., 1952; Enselberg and Lipkin, 1952; Zapata-Diaz et al., 1952; Shack et al., 1952; Lucas and Short, 1952). The present study was undertaken in order to evaluate the effects of procaine and procaine amide on the heart in the experimental animal and to assess the effectiveness of procaine amide in abolishing clinical arrhythmias. In a few cases a comparison was attempted of the relative value of procaine amide and quinidine.

\section{EXPERIMENTAL OBSERVATIONS}

A total of 35 experiments were performed in cats under dial anæsthesia. Electrocardiograms were recorded before and at frequent intervals after the administration of procaine hydrochloride ( $1 \%$ solution) or procaine amide (pronestyl, Squibb). The blood pressure and respiration were continuously recorded on a kymograph.

The Effects of Procaine and Procaine Amide Alone. Eleven cats received procaine and six cats procaine amide by the intravenous route. Single doses of 5-10 mg. per $\mathrm{kg}$. of either drug produced no significant changes in the electrocardiogram, blood pressure, or respiration. Amounts between 15 and $25 \mathrm{mg}$. per kg. of procaine or procaine amide given in single or in divided doses at 10-minute intervals produced depression of the $\mathrm{S}-\mathrm{T}$ segment with lowering of the $\mathrm{T}$ wave in about 50 per cent of the experiments and transient widening of the QRS complex in every experiment. Further increase in the dosage resulted in progressive widening of the QRS complex in every experiment; various degrees of heart block in about 90 per cent and ectopic beats in one-third of the experiments. An example is shown in Fig. 1. The sequence of events was similar in both groups, but whereas the early changes appeared after comparable doses of procaine and procaine amide on a weight basis (between 15 and $25 \mathrm{mg}$. per $\mathrm{kg}$.), much larger doses of procaine amide were necessary to produce irreversible widening of the QRS complex, heart block, and ectopic rhythm. These latter changes appeared after an average dose of $30 \mathrm{mg}$. per $\mathrm{kg}$. of procaine and $100 \mathrm{mg}$. per $\mathrm{kg}$. of procaine amide.

Lowering of the blood pressure was much more gradual when procaine amide was given and in two experiments up to 60 and $90 \mathrm{mg}$. per kg., respectively, we,e given before any appreciable drop in the blood pressure occurred. The average dose leading to cessation of the respiration and to an irreversible fall of the blood pressure to zero was $35 \mathrm{mg}$. per $\mathrm{kg}$. of procaine and $150 \mathrm{mg}$. per $\mathrm{kg}$. of procaine amide.

In five cats intracardiac procaine was administered in amounts of $15-25 \mathrm{mg}$. per $\mathrm{kg}$. The electrocardiographic changes observed differed in no way from those seen following intravenous administration of the 


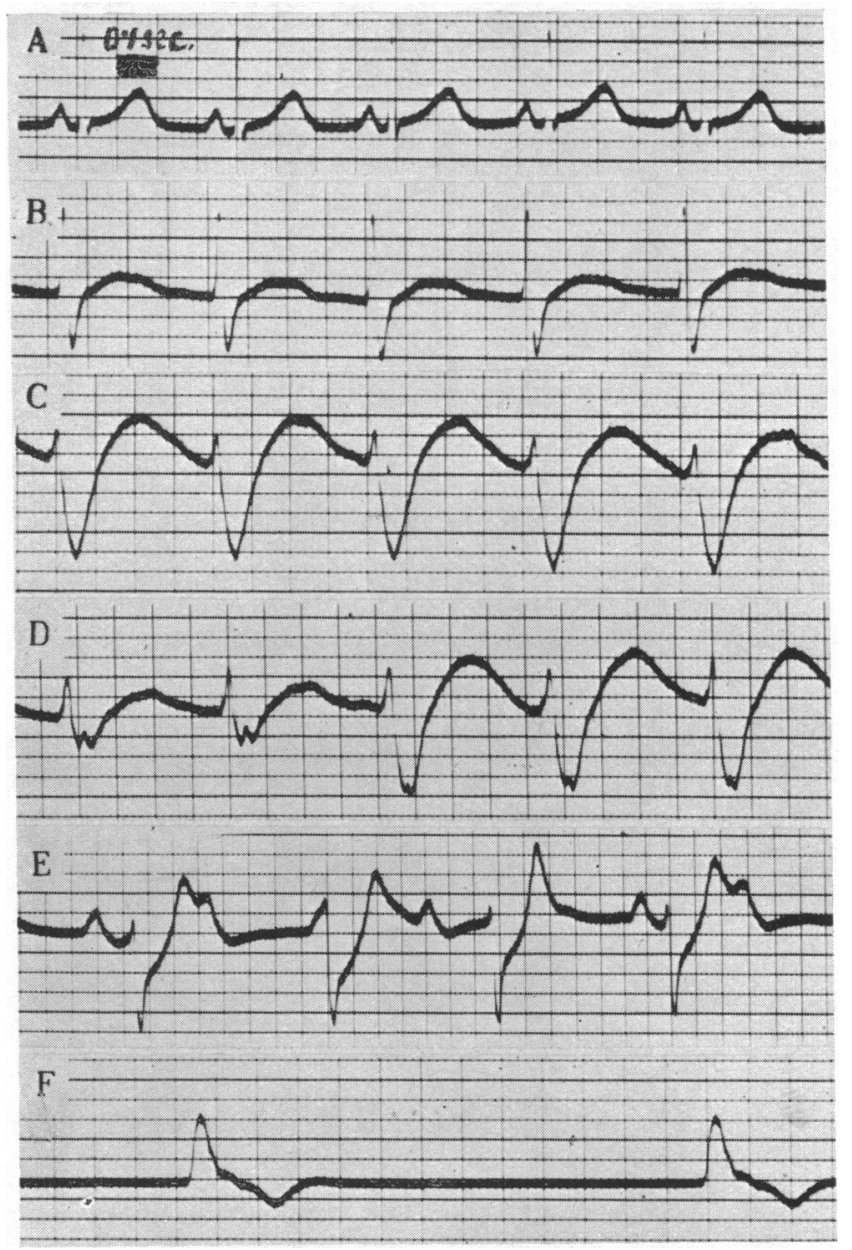

FIG. 1.-Cat, weight $1.8 \mathrm{~kg}$. lead II. Effects of intravenous procaine amide on the electrocardiogram. (A) Initial tracing. (B) After $30 \mathrm{mg}$. per $\mathrm{kg}$. Lowering of the $\mathrm{T}$ waves and widening of the QRS complex. (C) and (D) Continuous strips, after $150 \mathrm{mg}$. per kg. Progressive widening of the QRS complex. (E) After $180 \mathrm{mg}$. per kg. Complete A-V block. (F) 5 minutes after. (E) Slow idioventricular rhythm. No auricular activity.

drug. The most constant finding was progressive widening of the QRS complex which appeared in all five experiments.

In three cats thoracotomy was performed and a total of 30 and $35 \mathrm{mg}$. per $\mathrm{kg}$. of procaine and $250 \mathrm{mg}$. per $\mathrm{kg}$. of procaine amide, respectively, were injected into the pericardial cavity. In all experiments a characteristic " pericarditis pattern" appeared in the cardiogram (Fig. 2). There was some slowing of the heart rate, but no alteration in the duration of the QRS interval and no heart block in this set of experiments.

The Effects of Procaine and Procaine Amide after Vagotomy. In four cats bilateral vagotomy was performed before the intravenous administration of procaine or procaine amide. Amounts similar to those used in the group with intact vagi resulted in progressive widening of the QRS complex in all four experiments, complete heart block in two, and ventricular tachycardia in two experiments.

The Effects of Procaine and Procaine Amide on experimentally Induced Cardiac Arrhythmias. The action of intravenous procaine and procaine amide was studied on chloroform-adrenalin induced arrhythmias 


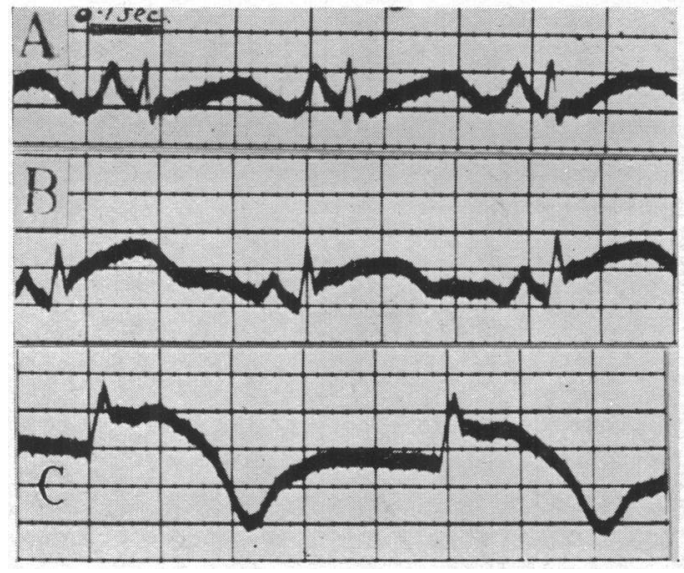

FIG. 2.-Cat, weight $2.6 \mathrm{~kg}$. lead II. (A) Initial tracing. (B) and (C) After the intrapericardial administration of $100 \mathrm{mg}$. per $\mathrm{kg}$. and $250 \mathrm{mg}$. per kg. of procaine amide. "Pericarditis pattern." No change in intraventricular conduction.

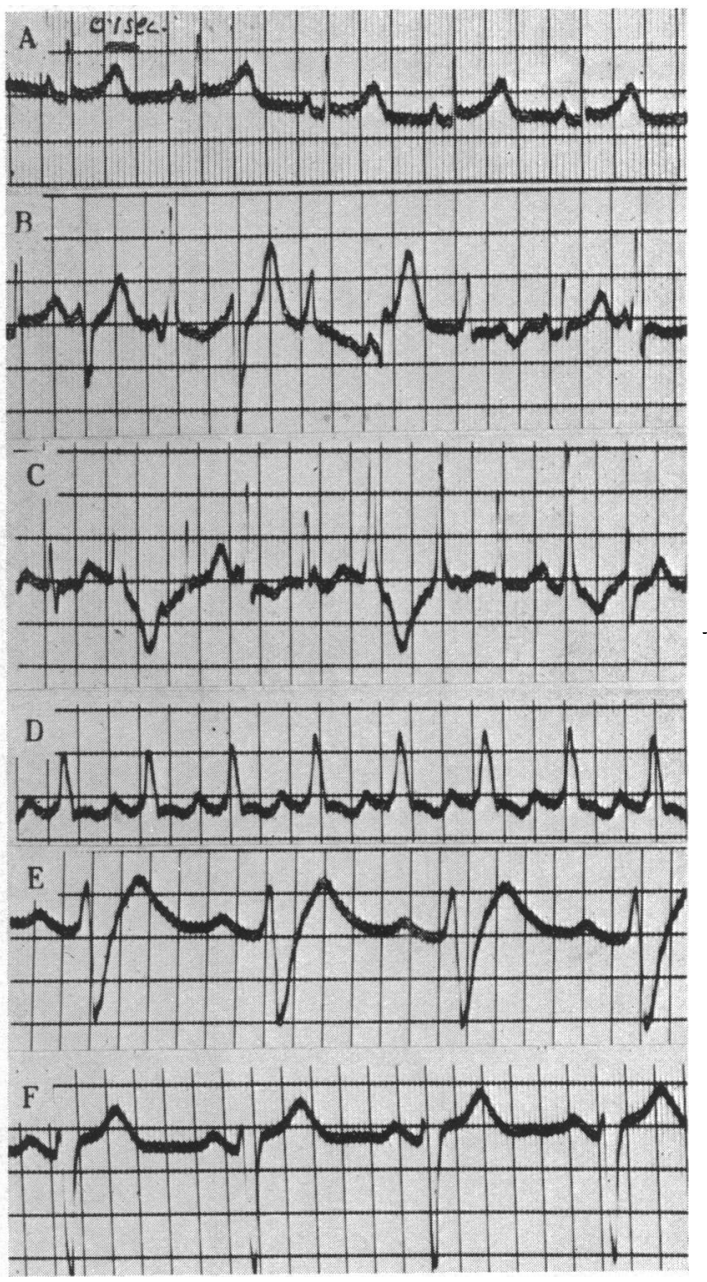

FIG. 3.-Cat, weight $2 \cdot 2 \mathrm{~kg}$. lead II. (A) Initial tracing. (B), (C), and (D) Continuous strips. Ectopic impulse formation induced by chloroform and adrenalin. (E) and (F) 1 and 2 minutes, respectively, following the intravenous administration of $15 \mathrm{mg}$. per $\mathrm{kg}$. of procaine. Ectopic rhythm eliminated and sinus rhythm restored.

in six cats. In three instances out of four an ectopic tachycardia was terminated by 15,20 , and $10 \mathrm{mg}$. per kg. of procaine, respectively (Fig. 3). In two experiments multifocal ventricular extrasystoles were eliminated by $20 \mathrm{mg}$. per $\mathrm{kg}$. of procaine and $60 \mathrm{mg}$. per $\mathrm{kg}$. of procaine amide, respectively.

\section{Clinical Observations}

Procaine amide was used in the treatment of 40 episodes of various types of cardiac arrhythmias occurring in 31 patients. In addition, the drug was given to six patients with sinus rhythm and normal P-R, QRS, and Q-T intervals in order to study its effects on normal conduction. In all but two instances procaine amide was given by mouth, one gram every 3 or 4 hours.

Extrasystoles. Three patients with four episodes of auricular extrasystoles and four patients with ventricular extrasystoles were studied. Two patients received procaine amide intravenously and five patients 
orally. The extrasystoles were abolished in all eight instances, but in one patient who had intravenous medication previous oral treatment was ineffective. The total effective oral dose ranged from 5 to $12 \mathrm{~g}$.; the effective intravenous dose was $200 \mathrm{mg}$. In one patient the extrasystoles reappeared within 24 hours after the drug was discontinued.

Auricular Fibrillation. Sixteen patients with auricular fibrillation received procaine amide by mouth. Sinus rhythm was restored in eight of them. The average dose required for conversion was $4.5 \mathrm{~g}$. The duration of auricular fibrillation before the administration of procaine amide was as a rule shorter in those patients in whom restoration of sinus rhythm was accomplished: it had been present for two months in three patients, three days in one patient, and less than 24 hours in four patients. On the other hand, in seven of the eight who failed to respond to procaine amide the arrhythmia had been present for many months or years; however, in the eighth it was known to have lasted only for two weeks. None of the eight patients in whom conversion to sinus rhythm was accomplished had received digitalis before procaine amide medication. Five patients in the unsuccessful group had been taking digitalis for three months or longer.

Paroxysmal Tachycardia. Seventeen episodes of paroxysmal tachycardia occurring in eleven patients were treated with procaine amide. Out of thirteen instances of supraventricular tachycardia sinus rhythm appeared in nine after an average dose of $6 \mathrm{~g}$.; on one occasion a slow nodal rhythm appeared; on another occasion the ventricular rate was halved and the auricular tachycardia persisted at the same rate; and on two occasions procaine amide had no effect whatsoever on the ectopic rhythm. In one patient a $2: 1$ auricular tachycardia was replaced during treatment by a $1: 1 \mathrm{~A}-\mathrm{V}$ conduction, but further medication resulted in restoration of sinus rhythm (Fig. 4).

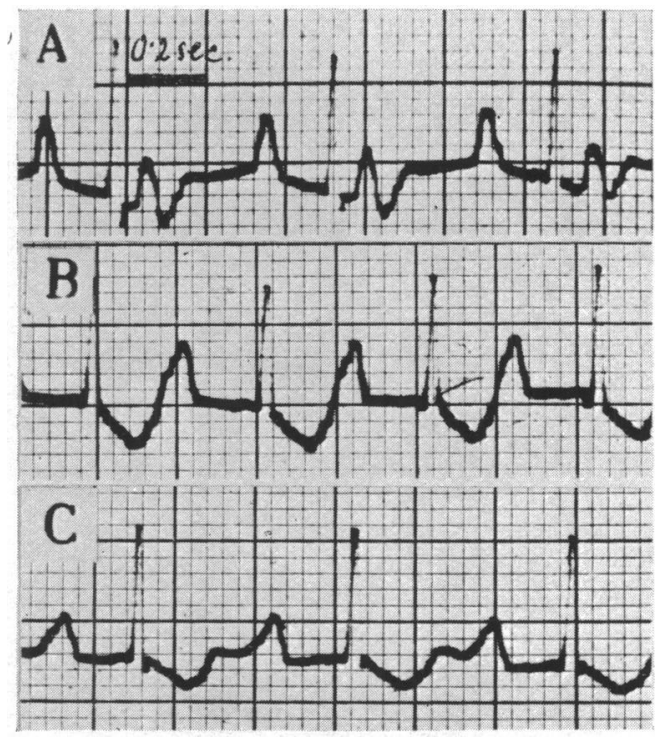

FIG. 4.-Lead II. (A) $2: 1$ auricular tachycardia. (B) After $2 \mathrm{~g}$. of procaine amide. Auricular tachycardia with $1: 1$ A-V conduction. (C) Sinus rhythm after $6 \mathrm{~g}$. of procaine amide.

Of the four patients with ventricular tachycardia three were successfully treated; the ectopic rhythm stopped and sinus rhythm appeared after 3, 9, and $12 \mathrm{~g}$. of procaine amide, respectively. In the fourth no result was achieved with $10 \mathrm{~g}$. and treatment had to be discontinued at this stage on account of marked nausea.

Procaine Amide and Quinidine. Six patients with recurrent arrhythmias were considered suitable for a comparison of the effects of oral procaine amide and quinidine. In two with auricular fibrillation both drugs were effective in restoring sinus rhythm. In two others with auricular fibrillation both drugs were ineffective; however, in one of them a previous attempt at conversion with quinidine a year earlier was 
successful. In two patients with practically daily paroxysms of supraventricular tachycardia we have attempted to assess the relative value of these two drugs in reducing the number of attacks. In one of these quinidine was of greater value than procaine amide, but in the other procaine amide appeared to be superior to quinidine.

The Effects of Procaine Amide on Normal Conduction. Six patients with sinus rhythm and normal P-R, $\mathrm{QRS}$, and Q-T intervals in the electrocardiogram were given $5 \mathrm{~g}$. of procaine amide in divided doses. The only changes observed were occasional increase in the length of the P-R interval and width of the QRS complex, but not beyond the limits of accepted normality.

\section{Discussion}

The experimental observations presented in this paper have confirmed the depressant action of procaine and procaine amide on the heart and they are in general agreement with previous studies. This action is not mediated by the vagus, since vagotomy did not eliminate or change it. McClendon et al. (1951) also concluded from hæmodynamic studies that procaine amide has a direct myocardial depressant action. The electrocardiographic changes in cats resulting from the intravenous administration of procaine and procaine amide were identical, the most constant findings being progressive widening of the QRS complex and heart block. However, procaine amide was tolerated in much larger doses than procaine. Newman and Clark (1950) have also found that procaine was a more potent respiratory depressant than procaine amide. For this reason procaine amide is a more suitable drug than procaine for the treatment of clinical arrhythmias. Furthermore, according to Harris et al. (1952) the depressant action of procaine amide on ectopic impulse formation is superior to that of procaine.

Several clinical and experimental studies have shown that procaine amide can be effective in the supraventricular tachycardias, including auricular fibrillation, as well as in ventricular tachycardia (Schlachman et al., 1951; Schaffer et al., 1951; McCord and Taguchi, 1951; Miller et al., 1952; Schack et al., 1952; Lucas and Short, 1952). Our own limited clinical observations favour this view. On the other hand, Enselberg and Lipkin (1952) stated in a recent publication that procaine amide showed a preferential action in ventricular arrhythmias.

An increase in the ventricular rate in auricular fibrillation and in auricular tachycardia with A-V block has occasionally been observed during procaine amide medication (McCord and Taguchi, 1951; Miller et al., 1952; Kelley et al., 1952; Zapata-Diaz et al., 1952). For this reason Kelley et al. (1952) and Miller et al. (1952) thought that it was advisable to give adequate doses of digitalis to patients with auricular fibrillation before giving procaine amide. We have seen a transient increase in the ventricular rate during procaine amide treatment in two patients; they did not receive digitalis. It is possible that adequate doses of digitalis will prevent an undesirable increase in ventricular rate during procaine amide medication. On the other hand, the question also arises whether long standing digitalization in auricular fibrillation can make conversion to sinus rhythm more difficult. Our present series is too small to enable us to draw conclusions on this point and further experience will be needed. According to Schack et al. (1952) digitalization has no significant effect on the response of the arrhythmia to procaine amide.

Procaine amide has a quinidine-like action (Wedd et al., 1951). According to Schaffer (1951) the anti-arrhythmic activity of procaine amide when given by mouth is about one-fourth that of quinidine on a weight basis. In our two cases of auricular fibrillation in which both procaine amide and quinidine have restored normal rhythm, the effective procaine amide dose was $4 \mathrm{~g}$. and $4.5 \mathrm{~g}$., and the effective quinidine dose was $3.5 \mathrm{~g}$. and $2.8 \mathrm{~g}$., respectively. Thus, the procaine amidequinidine ratios were 1.14 to 1 and 1.60 to 1 . Apart from nausea in several patients, procaine amide produced no untoward effects. However, the nausea was so pronounced in two patients that the drug had to be discontinued.

\section{SUMMARY}

In experiments in cats, the depressant action of procaine and procaine amide on conduction and on ectopic impulse formation was confirmed. 
Clinical observations, based on forty instances of various types of cardiac arrhythmias occurring in thirty-one patients, have confirmed the anti-arrhythmic property of orally administered procaine amide.

It is concluded that oral procaine amide is of value in the supraventricular tachycardias as well as in ventricular tachycardia.

Our thanks are due to Dr. W. G. A. Swan and to Professor A. A. Harper for their help and criticism. We also wish to acknowledge a grant received by one of us (N. A. W.) from the King's College (Newcastle) Research Fund.

\section{REFERENCES}

Berry, K., Garlett, E. L., Bellett, S., and Gefter, W. I. (1951). Amer. J. Med., 11, 431.

Burstein, C. L. (1946). Anaesthesiology, 7, 113.

Enselberg, C. D., and Lipkin, M. (1952). Amer. Heart J., 44, 781.

Harris, A. S., Estandia, A., Ford, T. J., Smith, H. T., Olsen, R. W., and Tillotson, R. F. (1952). Circulation, $5,551$.

Kelley, R. T., Keegan, C. E., and Katter, G. W. (1952). Amer. Heart J., 44, 851.

Kinsman, J. M., Hansen, W. R., and McClendon, R. L. (1951). Amer. J. med. Sci., 222, 365.

Lucas, B. G. B., and Short, D. S. (1952). Brit. Heart J., 14, 470.

McClendon, R. L., Hansen, W. R., and Kinsman, J. M.'(1951). Amer. J. med. Sci., 222, 375.

McCord, M. C., and Taguchi, J. T. (1951). Circulation, 4, 387.

Mark, L. C., Kayden, H. J., Steele, J. M., Cooper, J. R., Berlin, J., Rovenstine, E. A., and Brodie, B. B. (1951). J. Pharmacol., 102, 5.

Miller, G., Weinberg, S. L., and Pick, A. (1952). Circulation, 6, 41.

Newman, P. J., and Clark, B. B. (1950). Fed. Proc., 9, 304.

(1951). Fed. Proc., 10, 326.

Schack, J. A., Hoffman, I., and Vesell, H. (1952). Brit. Heart J., 14, 465.

Schaffer, A. I. (1951). Amer. Heart J., 42, 597.

, Blumenfeld, S., Pitman, E. R., and Dix, J. H. (1951). Amer. Heart J., 42, 115.

-, Steinman, R., and Scherf, D.'(1950). Cardiologia, 16, 342.

Schlachman, M., Benjamin, J. W., and Terranova, R. (1951). Amer. Heart J., 42, 284.

Stearns, N. S., Callahan, E. J., and Ellis, L. B. (1952). J. Amer. med. Ass., 148, 360.

Uhley, M. H., and Wilburne, M. (1948). Amer. Heart J., 36, 576.

Wedd, A. M., Blair, H. A., and Warner, R. S. (1951). Amer. Heart J., 42, 399.

Wiggers, C. J., and Wegria, R. (1940). Amer. J. Physiol., 131, 296.

Zapata-Diaz, J., Cabrera, C. E., and Méndez, R. (1952). Amer. Heart J., 43, 954. 